\title{
Safe cosmetics without animal testing? Contributions of the EU Project Sens-it-iv
}

\author{
Hans Ulrich Weltzien · Emanuela Corsini · Sue Gibbs • \\ Malin Lindstedt - Carl Borrebaeck • Petra Budde · Peter Schulz-Knappe • \\ Hermann-Josef Thierse $\cdot$ Stefan F. Martin · Erwin L. Roggen
}

Received: 12 September 2009/Published online: 24 November 2009

(C) The Author(s) 2009. This article is published with open access at Springerlink.com

\begin{abstract}
The 7th Ammendment to the Cosmetics Directive of the European Commission (Directive 76/ 768/EEC2) bans the marketing of cosmetics containing animal-tested ingredients since March 2009. Excepted are only tests for repeated dose toxicity, for which the animal ban will come into effect by 2013. One major concern for cosmetics, i.e. the risk of containing skin (contact) sensitizers, has in the past been addressed
\end{abstract}

Prof. Dr. H. U. Weltzien ( $₫)$

Max-Planck-Institute for Immunobiology,

Schillhof 5, 79110 Freiburg, Germany

e-mail: huweltzien@yahoo.de

E. Corsini Ph.D.

Laboratory of Toxicology, Department of Pharmacological

Sciences, University of Milan, Milan, Italy

Dr. S. Gibbs

Department of Dermatology, VU University Medical

Centre, Amsterdam, The Netherlands

Dr. M. Lindstedt - Prof. Dr. C. Borrebaeck

Department of Immunology, University of Lund,

Lund, Sweden

Dr. P. Budde · Dr. P. Schulz-Knappe

Proteome Sciences R\&D GmbH \& Co. KG,

Frankfurt, Germany

Dr. H.-J. Thierse

Department of Dermatology, University Medical Centre,

Mannheim, Germany

S. F. Martin Ph.D.

Department of Dermatology, University Medical Centre,

Freiburg, Germany

Dr. E. L. Roggen

Novozymes AS, Bagsvaerd, Denmark almost exclusively by animal testing. It is this problem attracting the central interest of the integrated research project Sens-it-iv (Novel Testing Strategies for in vitro Assessment of Allergens, http://www.sens-it-iv.eu), funded by the EC within framework 6 since October 2005. Here, the 28 Sens-it-iv partners from 10 European States present the 5 most promising types of in vitro assays selected for further refinement. These are: (1) a human epidermal equivalent (EE) model to rank contact allergens according to their sensitizing potency, (2) identification of contact sensitizers, including prohaptens, through intracellular production of IL-18 by the human keratinocyte cell line NCTC 2544, (3) determination of activation markers such as CD86, CD54 and most prominently CXCL8 (IL-8) on/in dendritic cell lines, (4) contact sensitizer-specific migration of MUTZ Langerhans cells towards the chemokine CXCL12, and (5) the allergen-specific activation and proliferation of naïve human T cells. Ongoing genomic and proteomic experiments are in the process of identifying larger sensitizer-specific biological marker signatures to be integrated into the above assays. We hope to supply the European control agencies with a basis for further validation of in vitro assays by the end of 2010 .

Keywords In vitro - Alternative - Sensitizer . Contact · Allergy $\cdot$ Cosmetic $\cdot$ Animal

Keine Tierexperimente in der EU: Bleiben Kosmetika sicher? Beiträge des EU-Projekts Sens-it-iv

Zusammenfassung Das "7th Ammendment to the Cosmetics Directive” der Europäischen Kommission 
untersagt seit März 2009 den Verkauf von Kosmetika, deren Bestandteile in Tierexperimenten getestet wurden. Einzige Ausnahme sind Tests auf "repeated dose toxicity”, für die das Verbot erst 2013 in Kraft tritt. Ein besonders für Kosmetika-Zusätze wichtiges, und bislang nur in Tierversuchen geprüftes, Gesundheitsrisiko liegt in der Sensibilisierung für Kontaktallergien. Das seit Oktober 2005 im 6. Rahmenprogramm der EU geförderte integrierte Forschungsprojekt Sens-it-iv (Novel Testing Strategies for in vitro Assessment of Allergens, http://www. sens-it-iv.eu) konzentriert sich besonders auf dieses Problem. Die 28 Partner aus 10 europäischen Staaten präsentieren hier fünf erfolgversprechende Typen von in vitro Testverfahren, die für die weitere Entwicklung ausgewählt wurden. Es sind dies (1) ein Toxizitätstest am Epidermal Equivalent (EE) Modell, der die Quantifizierung der allergenen Wirkung von Testsubstanzen erlaubt, (2) die Induktion von IL-18 in der Keratinozytenline NCTC 2544, mit welcher speziell Kontaktallergene, inklusive der sogenannten Prohaptene, entdeckt werden, (3) der Nachweis von Aktivierungsmarkern wie CD86, CD54 oder vor allem CXCL8 (IL-8) auf/in dendritischen Zell-Linien, (4) ein Migrationstest, der auf allergeninduzierter Wanderung von MUTZ Langerhans Zellen in Richtung des Chemokins CXCL12 beruht und (5) die Allergen-spezifische Aktivierung und Proliferation humaner T-Zellen. Laufende genomische und proteomische Großexperimente zielen auf die Definition zusätzlicher allergenspezifischer Marker -Signaturen, welche in die obigen Tests integriert werden können. Bis Ende 2010 hoffen wir den europäischen und nationalen Kontrollbehörden Grundlagen für Validierungsverfahren liefern zu können.

\section{Introduction}

The European Directive 86/609/EEC and the 7th Amendment to the Cosmetics Directive enforce an animal testing ban for all cosmetic ingredients since March 2009. Moreover, a marketing ban is in force for cosmetic products containing ingredients tested in animals for all endpoints except repeated dose toxicity, for which the deadline is 2013. Considerable efforts have therefore been initiated to develop in vitro alternatives for risk assessment (Hartung 2009), including the identification of potential allergenic sensitizers. One such effort is the European FP6 Integrated Project Sens-it-iv (1.10.2005-30.9.2010), entitled Novel Testing Strategies for in vitro Assessment of Allergens (http:/l www.sens-it-iv.eu). In vitro methods, despite persisting difficulties to completely simulate an in vivo immune system, have the advantage of circumventing interspecies differences by concentrating exclusively on human cell material. However, as yet validated in vitro alternatives are lacking, raising questions about the future safety of cosmetics. While final answers to this question have to come from national and international regulatory authorities, the scientific basis is to be laid by basic and applied research, not last within the Sens-it-iv consortium. It's 28 partners from academia, industry and special interest organizations focus on the in vitro identification of both, respiratory and skin sensitizers, but in the context of cosmetics we will here concentrate on our work concerning skin sensitization.

\section{The Sens-it-iv concept}

Sens-it-iv divides its efforts into a science (basic) and a technology (applied) module (Fig. 1). During the
Fig. 1 Work package organization of the Sens-it-iv consortium. The science module concentrates on basic understanding of lung and skin sensitization and characterization of the cellular components. $E C$ epithelial cells, $D C$ dendritic cells. After month 36 activities are increasingly transferred to the technology module with WP8 concentrating on the development of practical assays

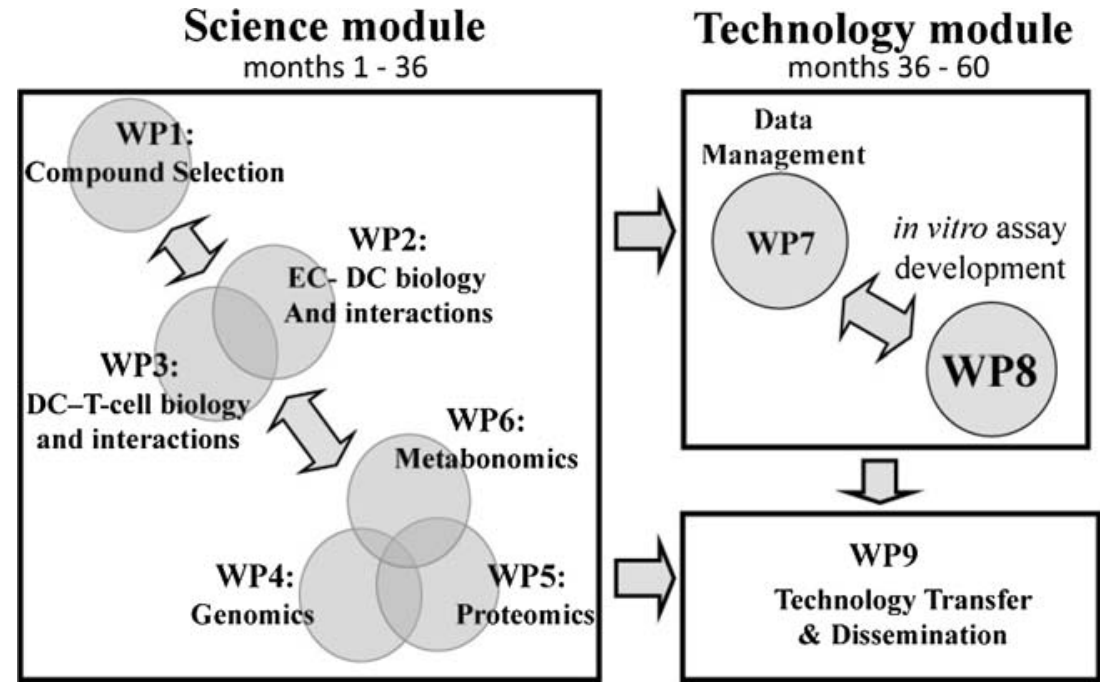


'basic research' phase (01.10.2005-30.09.2008), improved appreciation was obtained of the biological processes involved in the exposure of tissue to sensitizing materials. Within the 'applied research' phase (01.10.2008-30.09.2010) information of the science module is used to develop and standardize assay systems, which model sensitization of chemicals and proteins.

These activities are divided into nine work packages (WP) with WP1 laying the grounds by providing standardized samples and handling procedures of a list of tutorial chemicals, including respiratory and skin sensitizers, irritants and controls (list available under http://www.sens-it-iv.eu). WP2 and WP3 address the different cell types involved in sensitization as well as their mutual interactions, and WPs 4-6 deal with identifying new markers or metabolic pathways, respectively. The most promising assays were transferred into WP8 of the technology module to select the best cell lines and assure reproducibility between different laboratories, and those tests will be discussed below. WP progress is monitored in monthly newsletters under http://www.sens-it-iv.eu.

\section{Skin sensitization in vivo and corresponding predictive in vitro assays}

The major steps in the sensitization for contact sensitivity (Karlberg et al. 2008) are indicated in Fig. 2. Chemical allergens after penetration of the stratum corneum bind either directly (haptens) or upon metabolic transformation (pro-haptens) to proteins in the epidermis. Uptake and processing of these modified proteins by epidermal Langerhans cells (LC) is followed by maturation and migration of LC towards the draining lymph node where they activate allergen-specific T cells. The Sens-it-iv approach has dissected this process into several assays, which are also indicated in Fig. 2.

The first one mimics the penetration of the stratum corneum and general irritation of epidermal cells. The second refers to sensitizer-specific responses of epidermal keratinocytes. Tests of type number 3 study the induction of maturation markers on dendritic cells (DC) and corresponding human cell lines, and test number 4 addresses the induction of LC migration. Tests 5 and 6, finally, deal with activation and proliferation of $\mathrm{T}$ cells specific for individual sensitizing chemicals. While the latter assays are by nature not made to screen large panels of chemicals, they will be particularly helpful in determining the immunological responsiveness of humans to selected allergens.

\section{The EE potency assay}

To determine the allergenic potency of chemicals we developed a 3-dimensional epidermal-equivalent model (EE), which can be constructed from foreskin keratinocytes (Spiekstra et al. 2009). The great advantage of this model is that chemicals, independent of their solubility in water may be topically
Fig. 2 Major steps in skin sensitization and corresponding in vitro assays. Tests 1-6 (right) address different processes in the cause of skin sensitization (left)

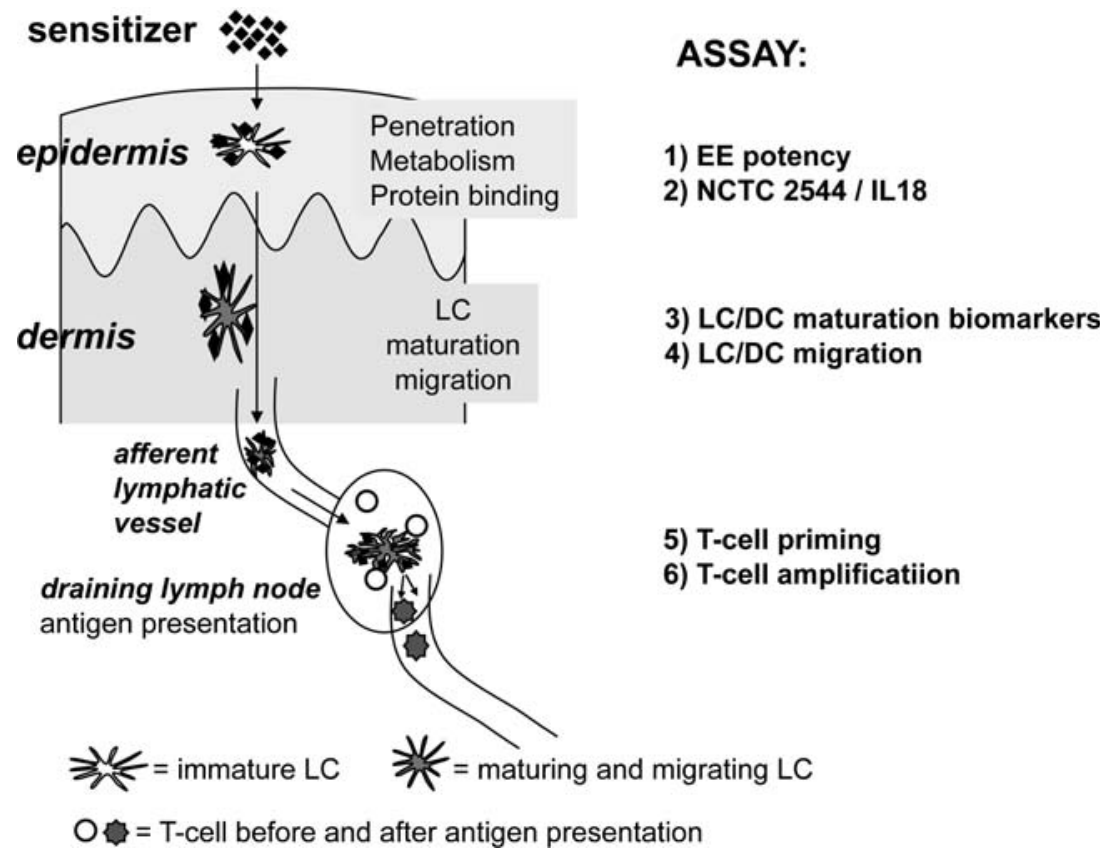




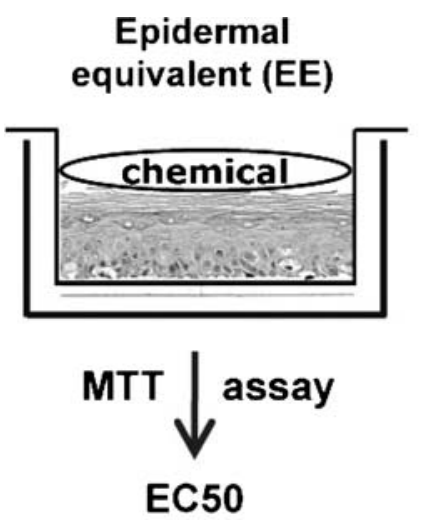

Fig. 3 Epidermal equivalent $(E E)$ potency assay (Spiekstra et al. 2009): correlation with LLNA. EE in double chamber cultures are topically exposed to chemicals via patch filters (left). After $24 \mathrm{~h}$ metabolical activity of the cultures is determined by MTT assay.

applied on the very same type of filter discs used in human patch testing. The readout is metabolic cell activity by the MTT color reaction and calculation of $\mathrm{EC}_{50}$ values (i. e. the concentration leading to $50 \%$ reduction of metabolic activity). This assay cannot differentiate irritants from allergens. However, when selectively applied to sensitizers identified by any of the other assays below, the majority of $\mathrm{EC}_{50}$ values correlates well with EC3 data derived in vivo by LLNA testing (Fig. 3), allowing a classification into strong, intermediate and weak sensitizers. Interestingly, none of the respiratory sensitizers tested so far was active in this assay (Spiekstra et al. 2009).

\section{Interleukin 18 (IL-18) production by keratinocytes}

Several years ago van Och et al. (2005) reported that human keratinocytes responded to sensitizers by increased production of IL-18. In our current view this may reflect a cleavage of inactive IL-18 precursor via activation of inflammasome located caspase 1 (Martinon et al. 2009). Determining intracellular IL-18 in the human keratinocyte cell line NCTC 2544 (Corsini et al. 2009) we now established an assay, which correctly detected all contact sensitizers of the Sens-it-iv tutorial chemicals (including the prohaptens eugenol, isoeugenol, cinnamic alcohol and paraphenylenediamine), and neither reacted to irritants nor to respiratory sensitizers (for examples see Fig. 4). A research proposal to pre-validate this approach is currently being submitted to ZonMW, The Netherlands.

\section{Correlation LLNA EC3 x EE EC50}

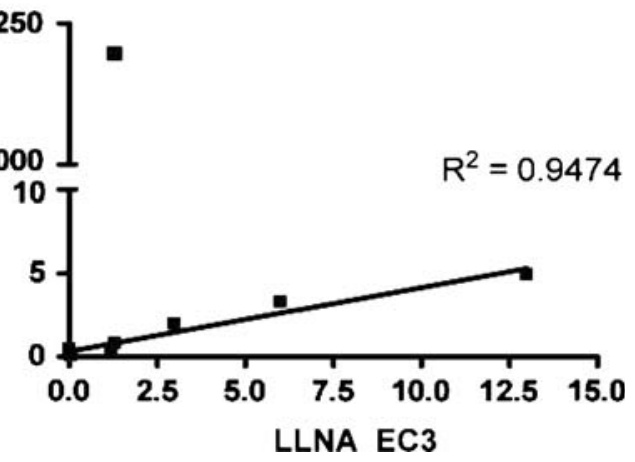

Concentrations for $50 \%$ reduction of metabolic activity (EC50 values) are deduced graphically and compared to EC3 values reported for the same chemicals for local lymph node assays (LLNA) (right)

\section{Maturation markers on dendritic cells}

Human dendritic cells can be prepared from peripheral blood monocytes (MoDC) in various maturation states. However, besides restricted lifetime and differences between individual donors also interlaboratory variation in the preparations may be significant. Established DC-like human cell lines such as THP-1, U937 or MUTZ-3 may overcome some of these problems (dos Santos et al. 2009), but on the other hand are even less likely to completely resemble all properties of DCs in vivo. A genomic comparison of different DCs and DC lines revealed significant differences in gene expression between all these cells, but identified MUTZ-3 as the cell line of relative closest similarity to in vivo conditions (Borrebaeck et al. unpublished). This and the fact that depending on culture conditions MUTZ-3 cells may be obtained in a variety of DC-typical maturation states, including LClike properties, made MUTZ-3 cells to the preferred DC line in our studies. Nevertheless, many experiments also include THP-1 or U937 cells (Python et al. 2009) and an ongoing ring trial in different laboratories compares their suitability in our various assays.

A number of sensitizer-specific maturation markers on DCs have been described such as the membrane proteins CD86 and CD54 (Python et al. 2009), the signaling protein p38 (Mitjans et al. 2008), or the secretion of interleukin 8 (IL-8, CXCL8) (Toebak et al. 2009), with the latter one found to be among the most promising in our hands. Figure 5 shows representative examples for IL-8 responses by MUTZ-3 cells to three different sensitizers and three non-sensitizers. 
Fig. 4 NCTC IL-18 assay

(Corsini et al. 2009). Sub-

confluent cultures of NCTC

2544 cells were treated for

$24 \mathrm{~h}$ with increasing non-

cytotoxic concentrations of

the selected chemicals. Cells

incubated with vehicle served

as control (0). Cell-associated

IL-18 was determined by ELISA

in cell lysates. Figures show

dose response effects of two

contact sensitizers

(cinnamaldehyde, $\mathbf{a}$ and

isoeugenol, b) two respiratory allergens (maleic

anhydride, $\mathbf{c}$ and

hexamethylenediisocyanate,

d), and two irritants (lactic

acid, e and salycilic acid, f).

Note different $y$-scales for A

and B. IL-18 data are shown as pg per mg of total lysate protein. Results are expressed as mean $\pm \mathrm{SD}, n=4$.

Statistical analysis was

performed with Dunnett's

multiple comparison test, with ${ }^{*} P<0.05$ and ${ }^{* *} P<0.01$

versus vehicle treated cells $(0)$

Fig. 5 CXCL8 (IL-8) secretion from MUTZ-3 cells. Data exemplify dose dependent secretion of IL- 8 by MUTZ-3 cells for two sensitizers (DNCB and cinnamaldehyde) and two irritants (salycilic acid and phenol). CXCL8 is expressed as ng per $10^{6}$ cells
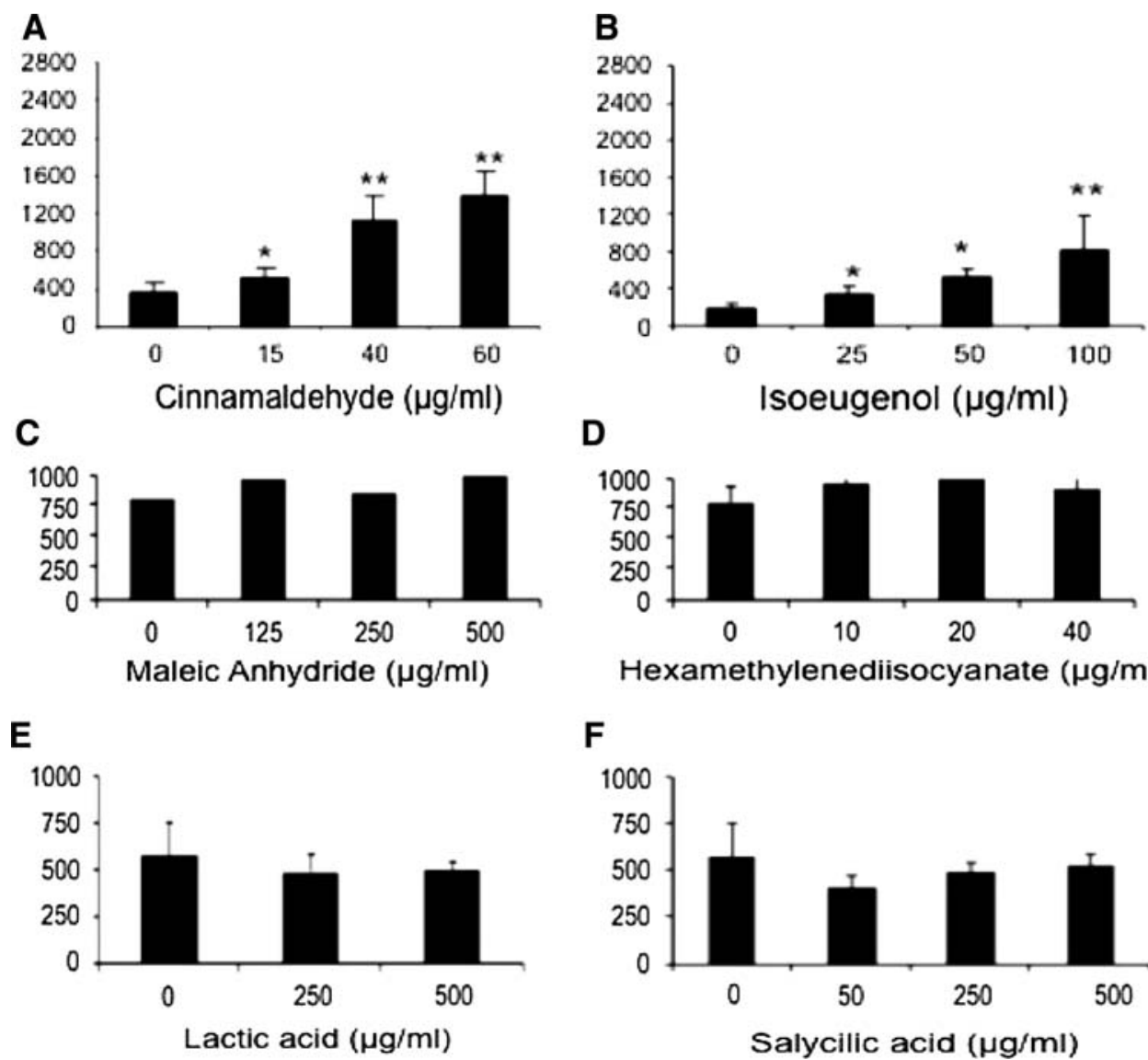

Hexamethylenediisocyanate $(\mu \mathrm{g} / \mathrm{ml})$

$\mathbf{F}$

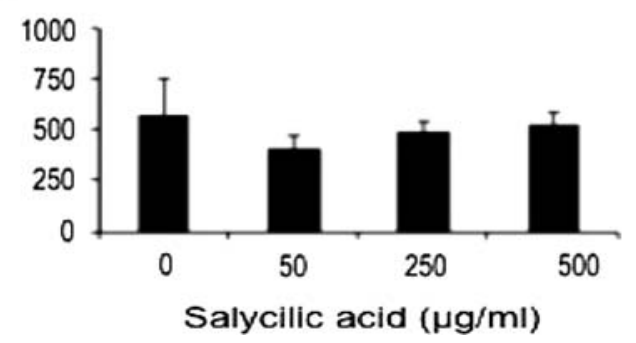

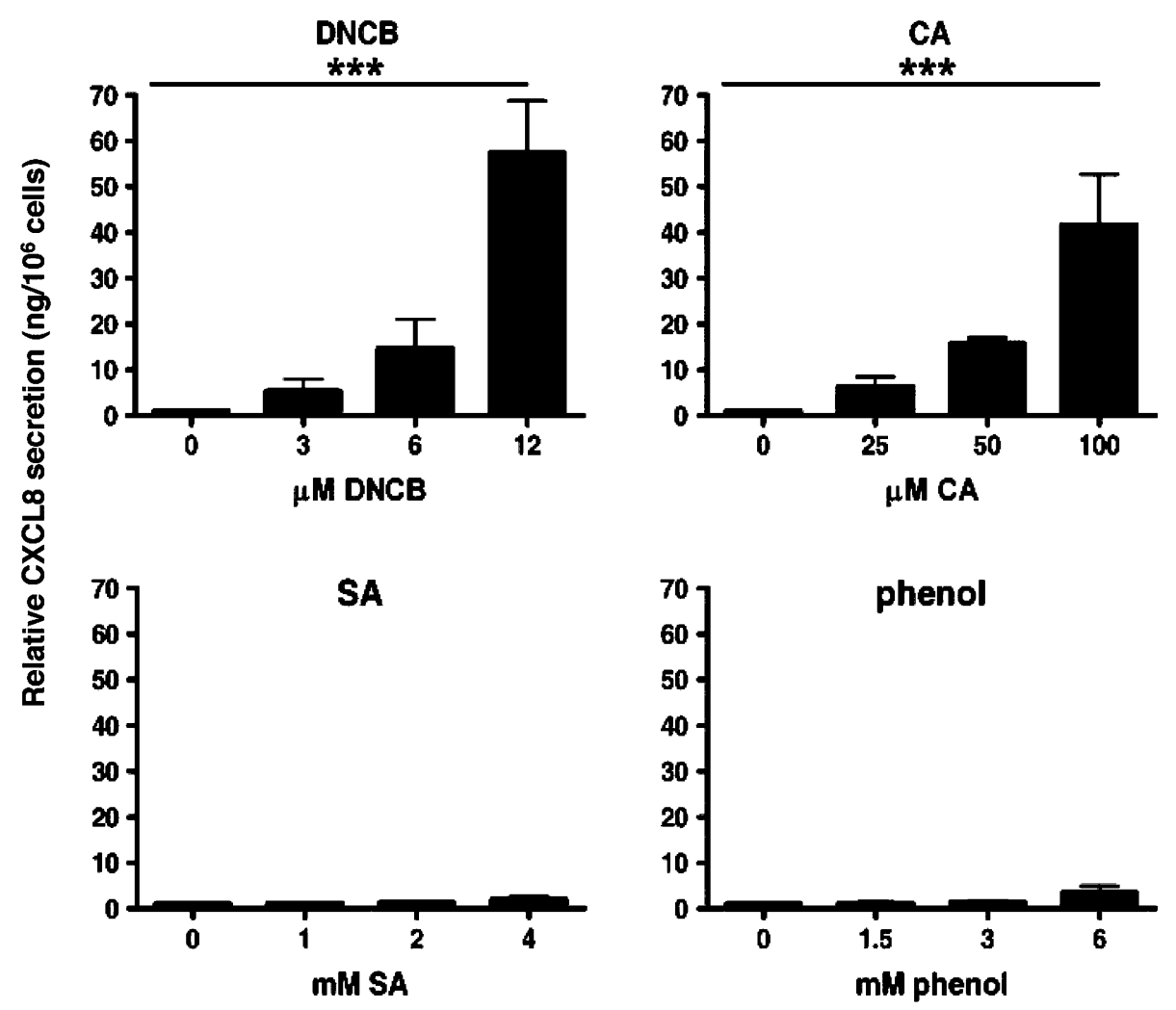




\section{LC/DC migration assay}

To simulate hapten-induced migration of LC from the epidermis to the dermis, a dual chamber experiment was designed. Fluorescently labeled (CSFE) MUTZ-LC in the upper compartment of a well will migrate through a porous filter toward fibroblasts growing on the bottom of the lower chamber where they may be collected and quantified. This migration depends on two fibroblast-derived chemokines, i.e. CXCL12 (Ouwehand et al. 2008) and CCL5 (manuscript submitted). Replacement of fibroblasts in the lower chamber by either of the two chemokines effectively retains this directed mobility. Pre-treatment of MUTZLC with sensitizers, but not with irritants induces the expression of a CXCL12 receptor and, hence, enhances migration towards CXCL12 without affecting CCL5 dependent migration. For every chemical the index of migration directed towards CXCL12 versus that directed towards CCL5 can be determined. An index of CXCL12:CCL5 $>1$, therefore, indicates sensitizers, values $<1$ non-sensitizers.

\section{T cell priming assay}

The final step of the sensitization phase in contact dermatitis is the activation of naïve T cells in the local lymph node. This step creates the remarkable structural specificity in the eventual elicitation phase by selecting and activating a minute fraction within the pool of available T cells. Each of these few cells carries a different, though functionally similar $\mathrm{T}$ cell antigen receptors (TCR) allowing a complementary fit to complexes of hapten-modified self-peptides and selfMHC molecules on the surface of DC or other antigen presenting cells (Weltzien et al. 1996; Martin 2004).

Our in vitro $\mathrm{T}$ cell priming assay employs MoDCs and sorted naïve T cells depleted of the $\mathrm{CD}_{2} 5^{+}$regulatory (suppressive) subpopulation of the same donor. MoDCs when modified by direct interaction with haptens or alternatively with hapten-protein adducts in co-culture drive hapten-specific $\mathrm{T}$ cells into proliferation and differentiation to produce interleukins such as interferon gamma (IFN-g). Combination with a polyclonal $\mathrm{T}$ cell amplification step (Geiger et al. 2009) before the addition of specific allergen can significantly increase the sensitivity of the system and allows for frequency determination of $\mathrm{T}$ cells of extremely rare specificities as well as for isolation and functional/genetical analysis of allergen-specific $\mathrm{T}$ cell clones.

As mentioned above, such assays may yield valuable information in situations not satisfactory clarified by other tests, while clearly not being developed for high throughput screening.

\section{9 “-Omics” Technologies}

All assays described above make use of maximally two or three marker molecules. Given the large number of potentially sensitizing chemicals and the different routes of their interaction with the immune system, significantly larger "signatures" of biological markers of allergenic stimulation may be required

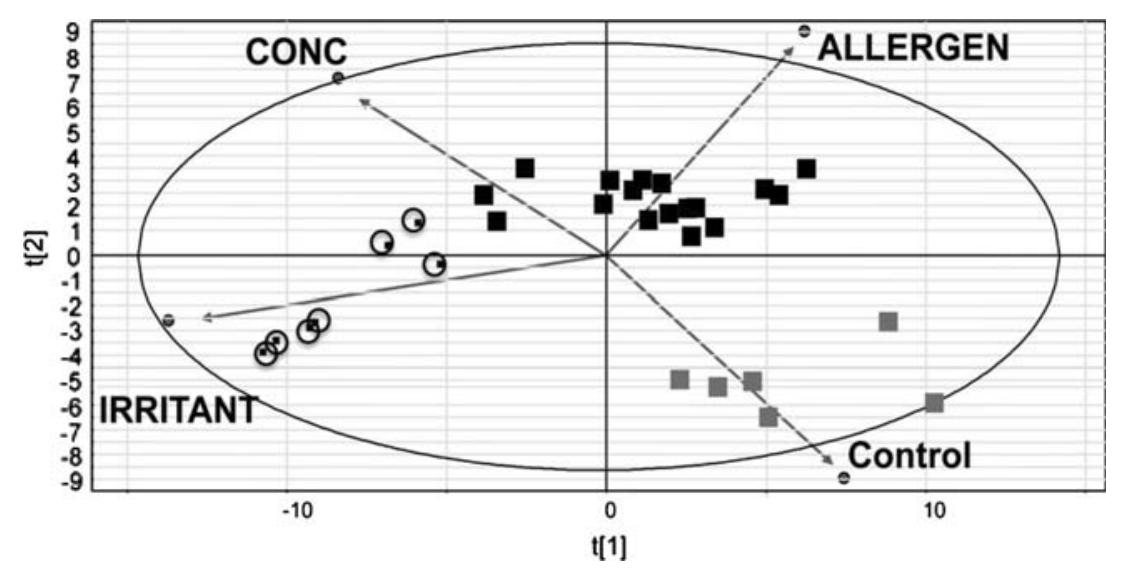

Fig. 6 Protein classification using partial least square (PLS) regression. Proteome-wide changes induced by chemical allergens in primary human keratinocytes were studied by $\mathrm{TMT}^{\circledR}$ based mass spectrometry (Schrader et al. 2006). PLS was used to classify chemicals based on cellular protein expression profiles. The analysis was carried out by encoding the experimental design (compounds and concentration) as Y-response vectors and the referenced protein abundance values of 153 proteins as $X$-vectors. Components 1 and 2 separate the samples into the three experimental groups. Filled squares allergens, gray squares controls, open circles irritants 


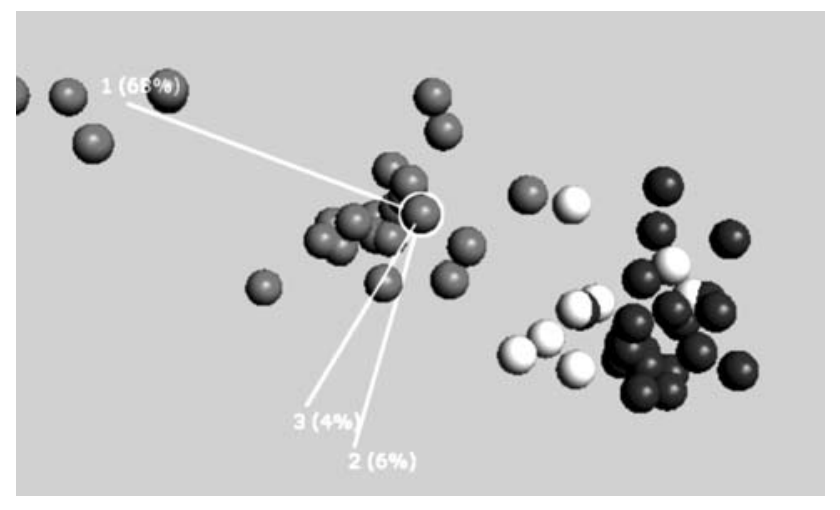

Fig. 7 Multi ANOVA analysis of gene-chip analyses of chemicaltreated MUTZ-3 cells. Filtering by treatment type, i.e. sensitizer (gray), non-sensitizer (white), control (black), results in impressive resolution particularly of the sensitizer-dependent genes

for effective risk assessment. Large genomic and proteomic data sets of allergen- and control-treated DCs and keratinocytes, partially obtained in parallel from the same experiments, are in the process of being analysed. Preliminary results from both groups of data reveal encouraging marker separations into sensitizer, irritant or control specific clusters (Figs. 6, 7). The time-lag between assay performance and the eventual supply of additional indicative markers has been bridged by freezing culture supernatants and RNA samples from most test models under study. In this way all materials may later be assayed for newly defined markers on RNA and/or protein level.

\section{Conclusions}

The EU ban of animal experiments for risk assessment of cosmetics by the 7th Amendment to the Cosmetics Directive has induced widespread activities in search for in vitro alternatives. There is general consensus that a combination of several functionally distinct human-based in vitro strategies can be successful and may eventually even surpass the accuracy of animal experiments. Following this route, several mechanistically relevant and promising test-strategies have been developed within the Sens-it-iv project and are being further refined. We see realistic chances to refine some of these assays to the stage where they can be formally evaluated and validated. The timing, however, to get these new technologies accepted by regulatory and legislative bodies lies outside the influence of Sens-it-iv. In that sense an answer to the original question concerning the future safety of cosmetics may depend on necessary interim solutions enforced by regulatory authorities.
Acknowledgments The authors gratefully acknowledge the contribution of all partners of the Sens-it-iv consortium. The integrated project Sens-it-iv (LSHB-CT-2005-018681: Novel Testing Strategies for In Vitro Assessment of Allergens) is funded within the sixth framework programme of the European Commission.

Open Access This article is distributed under the terms of the Creative Commons Attribution Noncommercial License which permits any noncommercial use, distribution, and reproduction in any medium, provided the original author(s) and source are credited.

\section{References}

Corsini E, Mitjans M, Galbiati V, Lucchi L, Galli CL, Marinovich M (2009) Use of IL-18 production in a human keratinocyte cell line to discriminate contact sensitizers from irritants and low molecular weight respiratory allergens. Toxicol In Vitro 23:769-796

dos Santos GG, Reinders J, Ouwehand K, Rustemeyer T, Scheper RJ, Gibbs S (2009) Progress on the development of human in vitro dendritic cell based assays for assessment of the sensitizing potential of a compound. Toxicol Appl Pharmacol 236:372-382

Geiger RT, Duhen T, Lanzavecchia A, Sallusto F (2009) Human naive and memory CD4 $+\mathrm{T}$ cell repertoires specific for naturally processed antigens analyzed using libraries of amplified T cells. J Exp Med 206:1525-1534

Hartung $T$ (2009) Toxicology for the twenty-first century. Nature 460:208-212

Karlberg AT, Bergström MA, Börje A, Luthman K, Nilsson JL (2008) Allergic contact dermatitis--formation, structural requirements, and reactivity of skin sensitizers. Chem Res Toxicol 21:53-69

Martin SF (2004) T lymphocyte-mediated immune responses to chemical haptens and metal ions: implications for allergic and autoimmune disease. Int Arch Allergy Immunol 134:186-198

Martinon F, Mayor A, Tschopp J (2009) The inflammasomes: guardians of the body. Annual Rev Immunol 27:229-265

Mitjans M, Viviani B, Lucchi L, Galli CL, Marinovich M, Corsini E (2008) Role of p38 MAPK in the selective release of IL-8 induced by chemical allergen in naive THp-1 cells. Toxicol In Vitro 22:386-395

Ouwehand K, Santegoets SJAM, Bruynzeel DP, Scheper RJ, de Gruijl TD, Gibbs S (2008) CXCL12 is essential for migration of activated Langerhans cells from epidermis to dermis. Eur J Immunol 38:3050-3059

Python F, Goebel C, Aeby P (2009) Comparative DNA microarray analysis of human monocyte derived dendritic cells and MUTZ-3 cells exposed to the moderate skin sensitizer cinnamaldehyde. Toxicol Appl Pharmacol 239:273-283

Schrader M, Budde P, Rose H, Lamping N, Schulz-Knappe P, Zucht H-D (2006) Peptidomics technologies and applications in drug research. In: Hamacher M, Marcus K, Stühler $\mathrm{K}$, van Hall A, Warscheid B, Meyer HE (eds) Proteomics in drug research. Wiley, Weinheim, pp 113-135

Spiekstra SW, Spiekstra SW, dos Santos GG, Scheper RJ, Gibbs S (2009) Potential method to determine irritant potency in vitro--comparison of two reconstructed epidermal culture models with different barrier competency. Toxicol In Vitro 23:349-355 
Toebak MJ, Gibbs S, Bruynzeel D, Scheper RJ, Rustemeyer T (2009) Dendritic cells: biology of the skin. Contact Derm 60:2-20

Van Och FM, Van Loveren H, Van Wolfswinkel JC, Machielsen AJ, Vandebriel RJ (2005) Assessment of potency of allergenic activity of low molecular weight compounds based on IL-1alpha and IL-18 production by a murine and human keratinocyte cell line. Toxicol Appl Pharmacol 210:95-109 Weltzien HU, Moulon C, Martin S, Padovan E, Hartmann U, Kohler J (1996) T cell immune responses to haptens. Structural models for allergic and autoimmune reactions. Toxicology 107:141-151 